\title{
Ultrasound examination before, during, and after office endometrial sampling
}

\author{
Thierry Van den Bosch • Dominique Van Schoubroeck • \\ Dirk Timmerman
}

Received: 14 September 2013 / Accepted: 27 November 2013/Published online: 10 December 2013

(C) Springer-Verlag Berlin Heidelberg 2013

\begin{abstract}
Office endometrial sampling is widely used as the first diagnostic test in women with abnormal uterine bleeding. Because office sampling is a blind procedure, the lesion causing the symptoms may be missed. The use of ultrasound before, during, and after office endometrial sampling improves relevant tissue yield. The measurement of the endometrial thickness informs if sampling is indicated. The evaluation of ultrasound features (without or with fluid instillation) may suggest a focal intracavitary lesion necessitating operative hysteroscopy. The knowledge of the uterine cavity length, shape, and flexion may avoid nonrepresentative sampling. The concordance between the tissue yield and the ultrasound findings reflects the reliability of the sampling. If not concordant, further diagnostic steps such as fluid instillation sonography or hysteroscopy are indicated. We conclude that integrating ultrasound in the diagnostic algorithm for uterine intracavitary pathology optimizes office endometrial sampling.
\end{abstract}

Keywords Ultrasonography · Uterus · Endometrium · Leiomyoma $\cdot$ Metrorrhagia

T. Van den Bosch · D. Van Schoubroeck · D. Timmerman Department of Development and Regeneration, KU Leuven, 3000 Leuven, Belgium

T. Van den Bosch

Department of Obstetrics and Gynecology, RZTienen, 3300 Tienen, Belgium

T. Van den Bosch $(\square)$

KU Leuven Department of Development and Regeneration, University Hospitals Leuven, Herestraat 49, 3000 Leuven, Belgium e-mail: thierry.van.den.bosch@skynet.be

\section{Background}

Most practitioners favor office endometrial sampling as the first diagnostic test in women with abnormal uterine bleeding. The main reason is that tissue diagnosis is considered pivotal. Depending on the histology of the endometrial sample, further management is planned. The alleged medico legal value of a pathology report is an additional reason in favor of endometrial biopsy. However, because office sampling is a blind procedure, there is no control that the tissue yielded is representative for the patient's problem. If a relevant lesion is missed, management is likely to be inappropriate.

Compared with other office sampling devices such as the Novak or the Vabra curette, the Pipelle ${ }^{\circledR}$ de Cornier [1] has been reported to cause less procedure-related pain while offering a similar diagnostic accuracy $[2,3]$. The popularity of the Pipelle ${ }^{\circledR}$ for office endometrial sampling dates from the early 1990s. Stovall et al. [4] reported in 1991 a $97.5 \%$ sensitivity of Pipelle ${ }^{\circledR}$ sampling for endometrial cancer. This study is not very robust since only 40 patients with known endometrial cancer were included. In 1993, Rodrigues et al. [5] measured the endometrial denudation by office sampling in hysterectomy specimens. By Pipelle ${ }^{\circledR}$, only $4.2 \%$ of the total endometrial surface was sampled and they conclude the method to be unreliable. In 2002, a systematic review by Clark et al. [6], on the accuracy of outpatient endometrial biopsy in the diagnosis of endometrial cancer, reported an excellent positive likelihood ratio of $66.5(95 \% \mathrm{CI}, 30.0-147.1)$ and a good negative likelihood ratio of 0.14 (95\% CI, 0.1-0.3). A possible explanation for the apparent contradiction between Rodrigues' and Clark's conclusions may be the tissue characteristics of endometrial cancer. Malignant endometrial tissue not only tends to protrude into the uterine cavity, it is also more friable because of less intercellular cohesion (Fig. 1). Tumor tissue is thus more prone to be aspirated during Pipelle ${ }^{\circledR}$ sampling. 


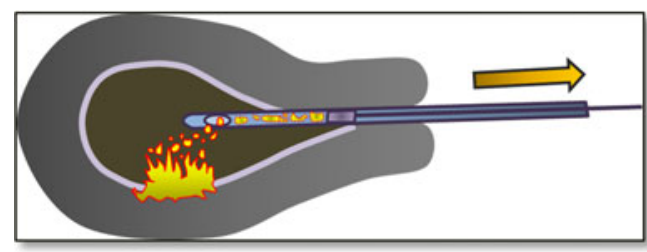

Fig. 1 Pipelle ${ }^{\mathbb{R}}$ aspiration biopsie of a focal malignant lesion

Endometrial cancer can be missed by office sampling [7]: small tumors or lesions hidden behind a benign focal lesion may escape the sampler. In the presence of intracavitary fluid or blood, the aspirated material may contain little or no endometrial cells (Fig. 2).

Many benign focal intracavitary lesions, such as endometrial polyps or intracavitary fibroids will not be picked-up by office sampling [8]. Although they are not life threatening, polyps and fibroids cause abnormal bleeding both before and after menopause. It is therefore relevant not to overlook benign focal lesions.

The value of ultrasound before, during, and after office endometrial sampling to improve relevant tissue yield will be discussed in this paper.

\section{Ultrasonography before endometrial sampling}

The indication for further testing in case of abnormal bleeding depends on different parameters: in postmenopausal women endometrial investigation may be indicated after a single episode of bleeding, whereas in younger women expectant management may be justified. After menopause, endometrial cancer is to be excluded first, whereas before menopause endometrial malignancy is much less likely. In women of reproductive age presenting with recurrent or persistent abnormal uterine bleeding, endometrial sampling may evidence endometrial hyperplasia, subacute endometritis or luteal dysfunction. However, this issue is beyond the scope of this paper. In this paper, it is assumed that further testing is clinically indicated. In case of (recurrent) abnormal uterine bleeding, the endometrial thickness is measured at transvaginal ultrasonography. If the endometrium is thin and uniform (Fig. 3), endometrial pathology is unlikely [9]. In those cases, endometrial sampling may not be necessary. The proposed threshold

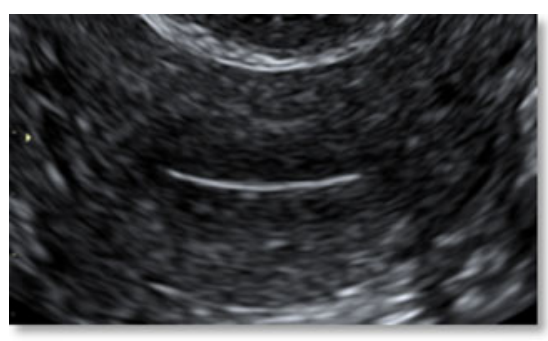

Fig. 3 Ultrasound image of a uniform thin endometrium

for total endometrial thickness above which further testing is indicated ranges from 3 to $5 \mathrm{~mm}$ [10-12].

The evaluation of the endometrium by ultrasound is not limited to an endometrial thickness measurement, but should include a detailed evaluation of the endometrial features at unenhanced ultrasonography, color Doppler imaging, and, if indicated, fluid instillation sonography (FIS), according the International Endometrial Tumor Analysis terms and definitions [13]. If a focal intracavitary lesion is seen, blind sampling is not the diagnostic test of choice because most endometrial polyps and intracavitary fibroids are missed at office sampling [8]. A hysteroscopical resection of these lesions is a more appropriate approach (Fig. 4).

If a diffuse thickening of the endometrium is seen or if endometrial cancer is suspected, office endometrial sampling is indicated. The endometrial thickness at ultrasonography should be correlated with the tissue yield at sampling: the thicker the endometrium, the higher the tissue yield is expected to be [14]. The tissue yield is related to the histology: the highest tissue yield in endometrial cancer, and the lowest tissue yield in endometrial atrophy [14]. To obtain a representative endometrial biopsy, the uterine cavity should be sampled, from the fundus to the endocervical canal. Although the clinician usually feels when the tip of the device touches the fundus, there are some pitfalls. A cesarean section scar defect, extreme uterine retroversion, or an intracavitary fibroid may misleadingly give the impression that the tip of the sampling device touches the fundus (Fig. 5).

The uterine cavity length, the uterine flexion, and the possible presence of an intracavitary fibroid or a cesarean section scar defect assessed by transvaginal ultrasound enable the clinician to ascertain that the sampling device will be introduced deep enough and that the endometrial sample will be representative. One should be aware that sampling disturbs the ultrasound features of the endometrium [15]. The
Fig. 2 Endometrial cancer missed by Pipelle ${ }^{\circledR}$ sampling in case of a a small lesion hidden behind a benign focal lesion and b in case of intracavitary fluid
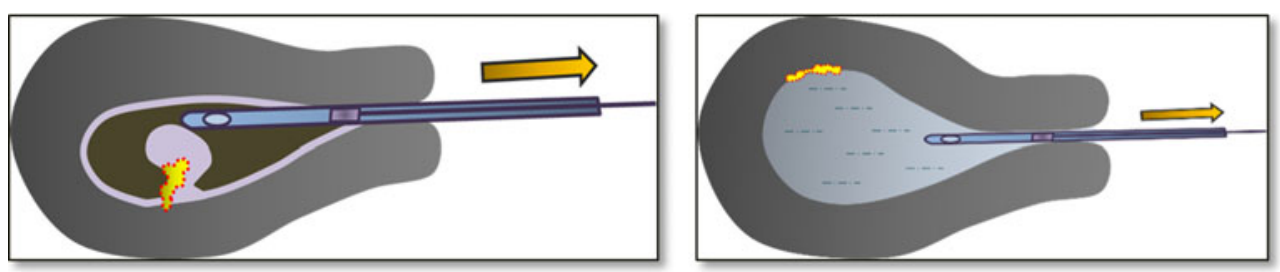
Fig. 4 Diagnostic algorithm

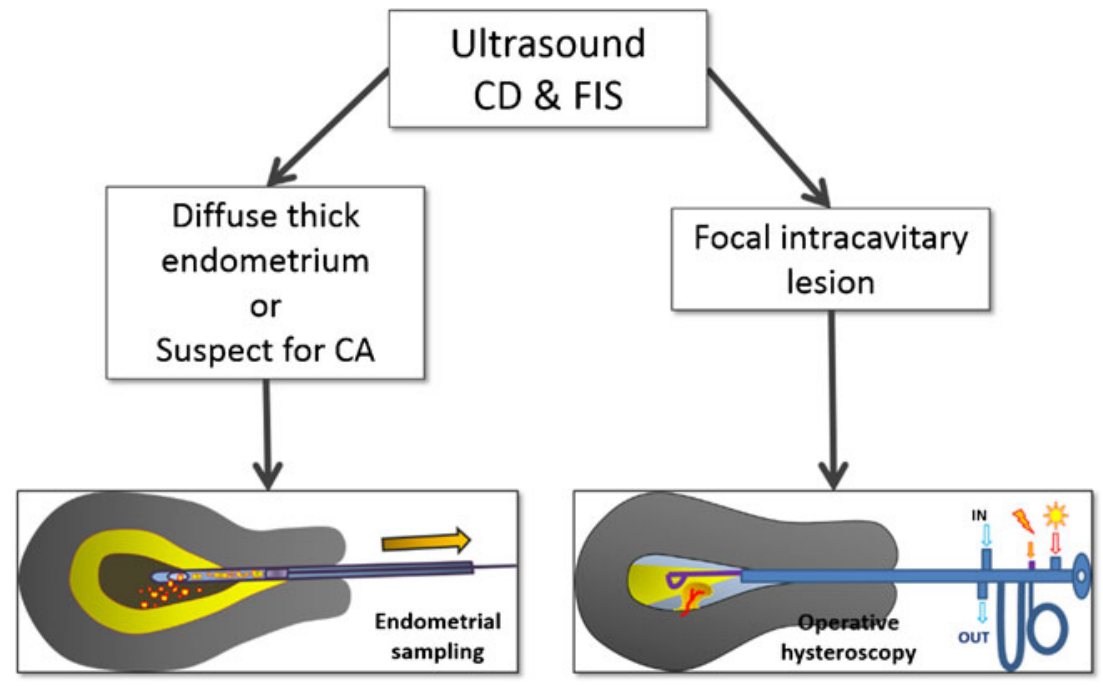

Fig. 5 Incomplete endometrial sampling in case of a cesarean scar defect, $\mathbf{b}$ severe uterine retroflection, $\mathbf{c}$ proximal benign focal intracavitary lesion
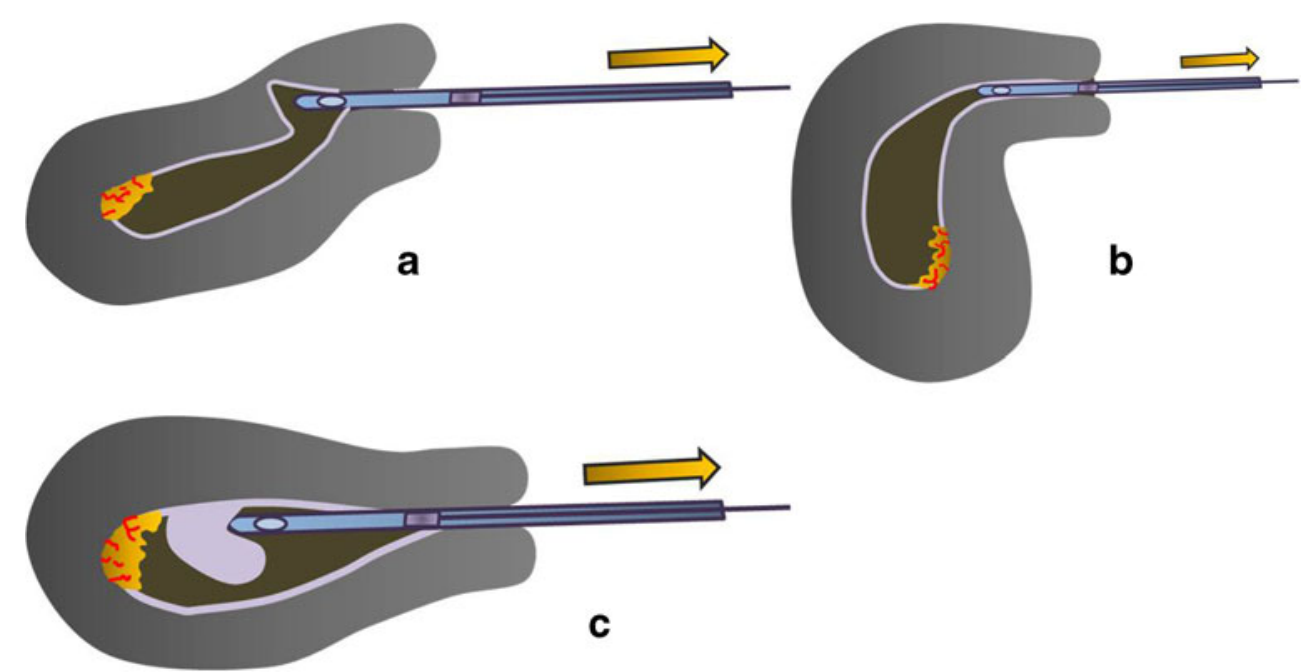

endometrial thickness, as well as other ultrasound characteristics such as the endometrial outline or the echogenicity of the endometrium is altered by the sampling procedure. This is another incentive to perform an ultrasound examination before proceeding with office endometrial biopsy.

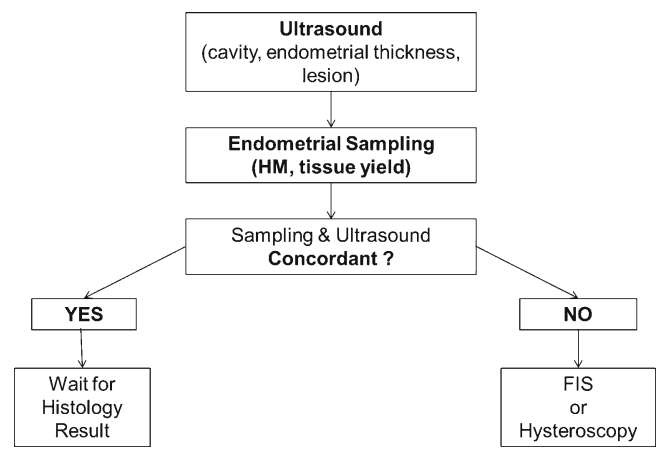

Fig. 6 Diagnostic algorithm based on ultrasound features and findings at endometrial sampling

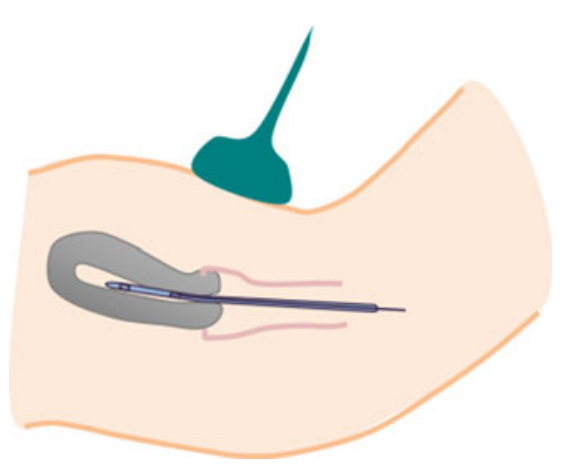

Fig. 7 Endometrial sampling under transabdominal ultrasound guidance 
Fig. 8 Pipelle sampling in case of intracavitary fluid

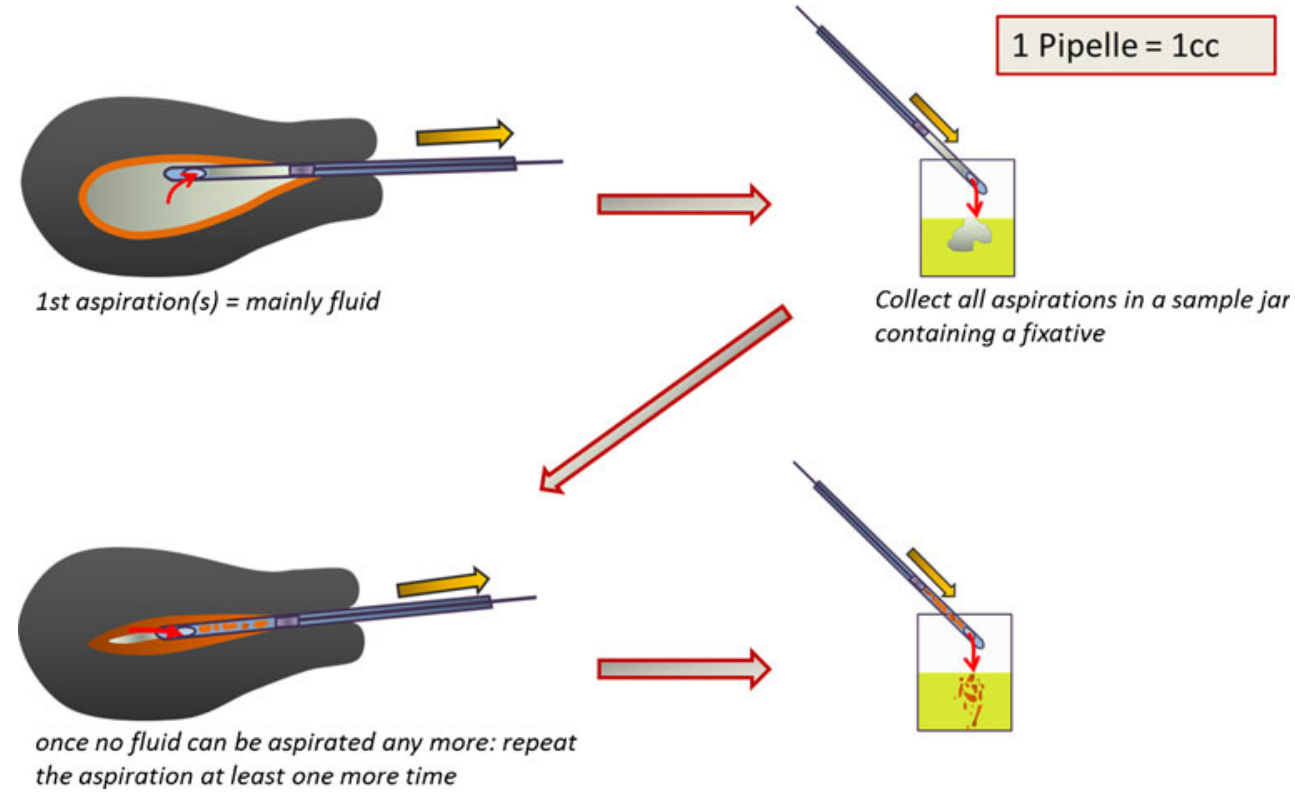

\section{Ultrasonography during endometrial sampling}

After having checked that the hysterometry on the sampling device matches the presampling ultrasound cavity length estimation, the actual tissue aspiration can be started. A Pipelle ${ }^{\circledR}$ sampler is a transparent device, allowing the estimation of the tissue yield during aspiration [14]. Endometrial tissue is visible as small whitish lumps, and can usually easily be differentiated from blood, pus, or mucus within the sampling device. The estimation of the amount of tissue retrieved during sampling correlates well with the tissue yield estimation of the pathologist [14]. Implementing a strict procedure for endometrium biopsy, including presampling ultrasound examination and assessment of the tissue yield during sampling (scored from 1 to 4 ), in 257 consecutive women with abnormal bleeding, the median endometrial thickness at ultrasound and the median tissue yield score was $18.3 \mathrm{~mm}$ and score 4 in the endometrial cancer cases, compared with $11.5 \mathrm{~mm}$ and score 2 in endometrial polyp cases, and $3.9 \mathrm{~mm}$ and score 1 in endometrial atrophy [14]. If the tissue yield is concordant with

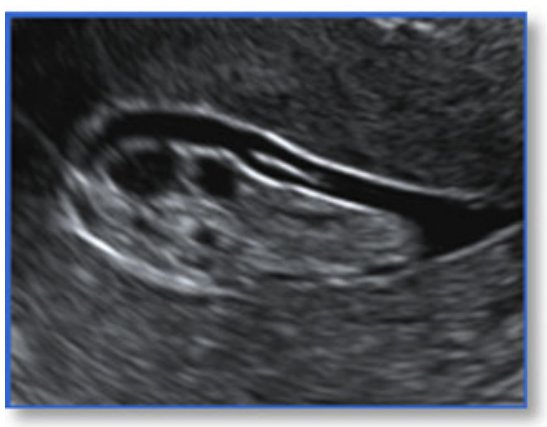

Fig. 9 Endometrial polyp diagnosed at fluid instillation sonography (FIS) the ultrasound findings (e.g., a thick endometrium and a high tissue yield), the histology result will most probably be reliable. If, on the other hand, the tissue yield is low in a patient with a thickened endometrium at ultrasonography, the lesion could have been missed and one cannot rely upon the histology result. Further testing, such as FIS with saline (SIS) or gel (GIS) [16], or hysteroscopy is needed (Fig. 6).

The insertion of the sampler may be difficult at times. This can be secondary to previous cervical surgery or due to retroversion of the uterus or to a cesarean section scar defect. In order to avoid a "fausse route" and to minimize patient's discomfort, endometrial sampling can be performed under ultrasound guidance. The direction of the sampler's insertion path is guided through transabdominal ultrasound (Fig. 7). This may be easier to do if the woman has some bladder filling.

\section{Ultrasonography after endometrial sampling}

Ultrasound examination after sampling should confirm the presampling ultrasound diagnosis: e.g., if the ultrasound image before sampling suggested the presence of blood or clots in the uterine cavity, an ultrasound examination after Pipelle ${ }^{\circledR}$

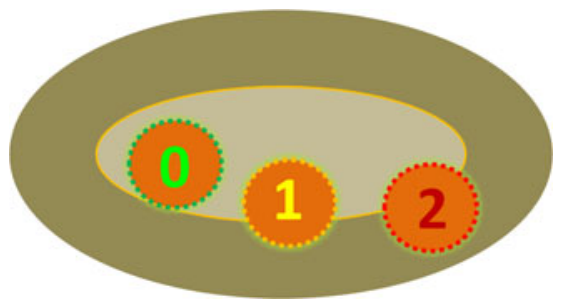

Fig. 10 Grading of intracavitary fibroids [13] 
aspiration can confirm that the clots have disappeared and that there are no residual focal lesions. In case of intracavitary fluid, it is important that the sampling is repeated till no fluid can be aspirated any more. Thereafter, at least one additional aspiration is performed for endometrial tissue sampling (Fig. 8).

The woman will hardly experience pain as long as the tip of the sampler is surrounded by fluid and does not touch the cavity wall. When there is no fluid in the cavity anymore, the endometrial mucosa will be sucked against the tip of the sampler, causing patient's discomfort or pain, especially if the endometrium is thin. In case of a thick endometrium at ultrasound and low tissue yield during sampling, a missed focal intracavitary lesion is to be suspected. One can immediately proceed with FIS to detect or exclude a focal lesion (Fig. 9).

Both FIS and hysteroscopy have a similar diagnostic accuracy for the detection of endometrial polyps and intracavitary fibroids [17].

In case of a focal intracavitary lesion, the ultrasound report should also provide additional information to tailor the operation. If one or more polyps are diagnosed, their size and number may determine whether a resection is to be performed as an outpatient's procedure or in theater under general anesthesia or sedation. If one or more fibroids are diagnosed, each lesions' size, grade (Fig. 10), and number should be documented accurately to allow estimation of the technical complexity of the resection procedure [18-25].

A fibroid larger than $2 \mathrm{~cm}$ or protruding less than $50 \%$ into the uterine cavity (grade 2) as well as the presence of more than one lesion are known to be technically challenging for the operative hysteroscopist. Ultrasound can give valuable information improving further management planning, such as the need for sedation or anesthesia, the expected operation time, and for informing the patient about the expected procedure's success rate (one or two step procedure).

\section{Conclusion}

Transvaginal ultrasound assessment of the uterine cavity informs the clinician if office endometrial sampling is indicated. If the endometrium is very thin and uniform, further testing may not be necessary. If a focal intracavitary lesion is detected, an operative hysteroscopy is warranted - not office sampling. The ultrasound examination also provides valuable information to plan the operative hysteroscopy. If endometrial sampling is to be performed, the ultrasound findings will improve sample quality. Incomplete insertion of the device can be avoided and the tissue yield during sampling can be anticipated by the endometrial thickness measured at ultrasound examination. The added value of ultrasound before, during, and after endometrial sampling should be validated in future studies.

We conclude that integrating ultrasound in the diagnostic algorithm for uterine intracavitary pathology optimizes endometrial sampling and allows quality control of the sampling procedure.

Conflict of interest Thierry Van den Bosch, Dominique Van Schoubroeck, and Dirk Timmerman declare that they have no conflict of interest.

Declaration of interest The authors report no conflicts in interest. The authors alone are responsible for the content and writing of the paper.

\section{References}

1. Cornier E (1984) The Pipelle: a disposable device for endometrial biopsy. Am J Obstet Gynecol 148:109-110

2. Kaunitz AM, Masciello A, Ostrowski M, Rovira EZ (1988) Comparison of endometrial biopsy with the endometrial Pipelle and Vabra aspirator. J Reprod Med 33:427-431

3. Hill GA, Herbert CM 3rd, Parker RA, Wentz AC (1989) Comparison of late luteal phase endometrial biopsies using the Novak curette or PIPELLE endometrial suction curette. Obstet Gynecol 73:443-445

4. Stovall TG, Photopulos GJ, Poston WM, Ling FW, Sandles LG (1991) Pipelle endometrial sampling in patients with known endometrial carcinoma. Obstet Gynecol 77:954-956

5. Rodriguez GC, Yaqub N, King ME (1993) A comparison of the Pipelle device and the Vabra aspirator as measured by endometrial denudation in hysterectomy specimens: the Pipelle device samples significantly less of the endometrial surface than the Vabra aspirator. Am J Obstet Gynecol 168:55-59

6. Clark TJ, Mann CH, Shah HM, Khan KS, Song F, Gupta JK (2002) Accuracy of outpatient endometrial biopsy in the diagnosis of endometrial cancer: a systematic quantitative review. BJOG 109:313-321

7. Van den Bosch T, Cornelis A (1998) Endometrial malignancy missed by office sampling. Aust N Z J Obstet Gynaecol 38:1-2

8. Van den Bosch T, Vandendael A, Van Schoubroeck D, Wranz PAB, Lombard CJ (1995) Combining vaginal ultrasonography and office endometrial sampling in the diagnosis of endometrial disease in postmenopausal women. Obstet Gynecol 85:349-352

9. Van den Bosch T, Van Schoubroeck D, Vergote I, Moerman P, Amant F, Timmerman D (2007) A thin and regular endometrium on ultrasound is very unlikely in patients with endometrial malignancy. Ultrasound Obstet Gynecol 29:674-679

10. Smith-Bindman R, Kerlikowske K, Feldstein VA, Subak L, Scheidler J, Segal M, Brand R, Gracy D (1998) Endovaginal ultrasound to exclude endometrial cancer and other endometrial abnormalities. JAMA 280:1510-1517

11. Tabor A, Watt HC, Wald NJ (2002) Endometrial thickness as a test for endometrial cancer in women with postmenopausal vaginal bleeding. Obstet Gynecol 99:663-670

12. Timmermans A, Opmeer B, Khan K, Bachmann LM, Epstein E, Clark JT, Gupta JK, Bakour SH, Van den Bosch T, van Doorn HC, Cameron ST, Giusa MG, Dessole S, Dijkhuizen FPHLJ, ter Riet G, Mol WJ (2010) Endometrial thickness measurement for detecting endometrial cancer in women with postmenopausal bleeding: a systematic review and meta-analysis. Obstet Gynecol 116:160-167

13. Leone F, Timmerman D, Bourne T, Valentin L, Epstein E, Goldstein SR, Marret H, Parsons AK, Gull B, Istre O, Sepulveda W, Ferrazzi E, 
Van den Bosch T (2010) Terms, definitions and measurements to describe the sonographic features of the endometrium and intrauterine lesions: a consensus opinion from the International Endometrial Tumor Analysis (IETA) group. Ultrasound Obstet Gynecol 35:103112

14. Van den Bosch T, Van Schoubroeck D, Van Calster B, Cornelis A, Timmerman D (2012) Pre-sampling ultrasound evaluation and assessment of the tissue yield during sampling improves the diagnostic reliability of office endometrial biopsy. J Obstet Gynaecol 32:173176

15. Van den Bosch T, Van Schoubroeck D, Timmerman D (2005) Ultrasound examination of the endometrium before and after Pipelle $^{\circledR}$ endometrial sampling. Ultrasound Obstet Gynecol 26: 283-286

16. Werbrouck E, Veldman J, Luts J, Van Huffel S, Van Schoubroeck D, Timmerman D, Van den Bosch T (2011) Detection of endometrial pathology using saline infusion sonography versus gel instillation sonography: a prospective cohort study. Fertil Steril 95:285-288

17. de Kroon C, De Bock GH, Dieben SWM, Jansen FW (2003) Saline contrast hydrosonography in abnormal uterine bleeding: a systematic review and metaanalysis. BJOG 110:938-947

18. Wamsteker K, Emanuel MH, de Kruif JH (1993) Transcervical hysteroscopic resection of submucous fibroids for abnormal uterine bleeding: results regarding the degree of intramural extension. Obstet Gynecol 82:736-740

19. Emanuel MH, Wamsteker K, Hart AA, Metz G, Lammes FB (1999) Long-term results of hysteroscopic myomectomy for abnormal uterine bleeding. Obstet Gynecol 93:743-748

20. Cravello L, Agostini A, Beerli M, Roger V, Bretelle F, Blanc B (2004) Results of hysteroscopic myomectomy. Gynecol Obstet Fertil 32:825-828, Article in French

21. Marret H, Cottier JP, Alonso AM, Giraudeau B, Body G, Herbreteau D (2005) Predictive factors for fibroids recurrence after uterine artery embolisation. BJOG 112:461-465

22. Di Spiezio SA, Mazzon I, Bramante S, Bettocchi S, Bifulco G, Guida M, Nappi C (2008) Hysteroscopic myomectomy: a comprehensive review of surgical techniques. Hum Reprod Update 14:101-119

23. Rovio PH, Helin R, Heinonen PK (2009) Long-term outcome of hysteroscopic endometrial resection with or without myomectomy in patients with menorrhagia. Arch Gynecol Obstet 279:159-163

24. Camanni M, Bonino L, Delpiano EM, Ferrero B, Migliaretti G, Deltetto F (2010) Hysteroscopic management of large symptomatic submucous uterine myomas. J Minim Invasive Gynecol 17:59-65

25. Lasmar RB, Xinmei Z, Indman PD, Celeste RK, Di Spiezio SA (2011) Feasibility of a new system of classification of submucous myomas: a multicenter study. Fertil Steril 95:2073-2077 